Chinese Journal of Organic Chemistry

\title{
$\alpha$-酮酸在无金属有机光合成中的应用
}

\author{
谢坤宸 ${ }^{\dagger}$ 江铭轩 ${ }^{\dagger}$ 陈晓岗吕琪妍* 於兵* \\ (郑州大学化学学院 绿色催化中心 郑州 450001)
}

\begin{abstract}
摘要 $\alpha$-酩酸作为一种羧酸, 可以通过脱羧作用, 作为酰基化试剂应用于有机合成, 但是传统方法往往依赖过渡金属 催化剂或高温等反应条件, 在一定程度上限制了其应用. 近年来发展的可见光诱导的有机反应由于条件温和及易于操 作等优点而受到广泛关注. 综述了无金属条件下可见光诱导的 $\alpha$-酮酸的相关反应研究进展, 主要包括在酰基化反应和 环化反应中的应用.

关键词 $\alpha$-酮酸; 可见光; 无金属催化; 酰基化
\end{abstract}

\section{Application of $\alpha$-Keto Acids in Metal-Free Photocatalysis}

\author{
Xie, Kunchen ${ }^{\dagger} \quad$ Jiang, Mingxuan ${ }^{\dagger} \quad$ Chen, Xiaolan $\quad$ Lü, Qiyan* ${ }^{*} \quad$ Yu, Bing* \\ (College of Chemistry, Zhengzhou University, Zhengzhou 450001)
}

\begin{abstract}
As a carboxylic acid, $\alpha$-keto acid can be used as an acylating reagent by decarboxylation in organic synthesis. However, traditional methods often need transition metal catalysts or high temperatures, which limits the application of $\alpha$-keto acid to a certain extent. In recent years, organic transformations induced by visible light have attracted extensive attention due to its mild conditions and simple operations. Herein, the recent advances of metal-free photocatalytic application of $\alpha$-keto acids are summarized, which mainly include acylation reactions and cyclization reactions.
\end{abstract}

Keywords $\alpha$-keto acid; visible light; metal-free catalysis; acylation

羧酸是一类重要的化学原料, 具有易得、低毒和稳 定等优点, 在有机合成中得到了广泛应用. 其中, $\alpha$-酩 酸是一类特殊的羧酸, 通常在脱羧偶联反应中作为酰基 化试剂(图 1) ${ }^{[1,2]}$. 但是, 传统方法往往使用过渡金属催 化剂或者需要高温等苛刻的反应条件. 因此, 开发更加 绿色、温和的脱羧偶联新方法具有重要意义.

近年来, 可见光促进的有机合成有效避免了传统有 机反应的苛刻条件, 已经成为当前的研究前沿和热点领 域 ${ }^{[3-13]}$. 通过可见光促进反应的策略, 人们开发了许多 新型高效的有机合成方法 ${ }^{[14-25]}$. 特别值得注意的是, 雷 爱文等 ${ }^{[26]}$ 在 2014 年以 $\left[\mathrm{Ru}(\mathrm{phen})_{3}\right] \mathrm{Cl}_{2}$ 为光催化剂在可见 光照射下实现了 $\alpha$-酮酸与伯胺的脱羧/氧化胺化反应, 在温和条件下实现了酰胺键的构建. 此后, 可见光诱导 $\alpha$-酮酸的脱羧偶联反应引起了人们的进一步关注.

由于贵金属光催化剂的价格昂贵, 且产物在纯化的
过程中容易产生金属残留等问题，近年来，人们发展了 多种无金属的有机光催化剂用于可见光诱导 $\alpha$-酮酸类 化合物的化学转化. 图 1 中列举了近年来光催化 $\alpha$-酮酸 脱羧的有机光催化剂, 包括曙红 B (eosin B)、罗丹明 B (rhodamine B) 和孟加拉玫瑰红(rose bengal)等. 本文综 述了无金属光催化剂作用下，可见光诱导 $\alpha$-酮酸类化合 物的脱羧反应的最新进展，主要包括: (1) $\alpha$-酮酸在酰化 反应中的应用, (2) $\alpha$-酮酸在环化反应中的应用, (3)其他 反应.

\section{$1 \alpha$-酮酸在酰化反应中的应用}

炔酮类化合物是重要的合成砌块，可用作合成呋 喃、吡唑及黄酮等杂环的前体. 由于炔酮类化合物的重 要作用, 人们发展了多种合成方法. 但是, 传统方法往 往需要高温或使用金属催化剂和添加剂[27]. 2015 年, 王

\footnotetext{
* Corresponding authors. E-mail: qiyanlv@zzu.edu.cn; bingyu@zzu.edu.cn

Received September 4, 2021; revised October 13, 2021; published online October 20, 2021.

Project supported by the National Natural Science Foundation of China (Nos. 21971224, 22171249), the Innovation and Entrepreneurship Training Program (Nos, S202110459196, 2021 cxcy197) and the Top Undergraduates Program of Zhengzhou University.

国家自然科学基金(No. 21971224, 22171249)、大学生创新创业训练计划(No. S202110459196, 2021cxcy197)和郑州大学本科生拔尖计划资助项目.

$\dagger$ 共同第一作者(These authors contributed equally to this work).
} 


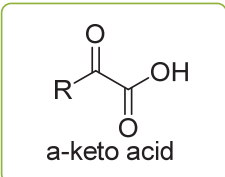<smiles>CN=c1ccc2cc3ccc(NC)cc3oc-2c1</smiles>

acridine red<smiles>O=c1c2ccccc2sc2ccc(Cl)cc12</smiles>

2-chloro-thioxanthen-9-one (Cl-TXO)<smiles></smiles><smiles></smiles>

rhodamine B

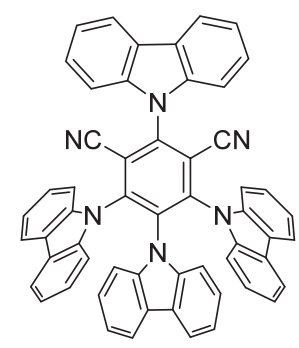

4CZIPN

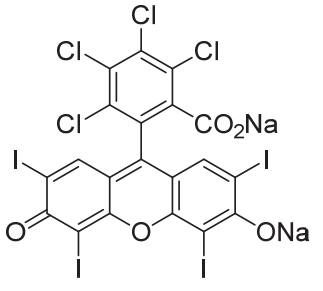

rose bengal

图 $1 \alpha$-酮酸及其脱羧反应中的有机光催化剂的结构

Figure 1 Structures of $\alpha$-keto acid and organophotocatalyst for its decarboxylation

磊课题组 ${ }^{[28]}$ 报道了一种日光照射下以炔溴和 $\alpha$-酮酸为 原料合成炔酮的方法. 该方法以 1-羟基-1,2-苯碘酰$3(1 H)$-酮(BI-OH)为催化剂, 甲苯为溶剂, 避免了金属试 剂和光催化剂的使用. 在可能的反应机理中, $\alpha$-酮酸首 先与 BI-OH 反应生成中间体 1a. 1a 随后在光照下脱羧生
成酰基自由基 $1 \mathrm{~b}$ 和自由基 $1 \mathrm{c}$. 自由基 $1 \mathrm{c}$ 接着与炔溴 $1 \mathrm{~d}$ 反应生成中间体 $1 \mathrm{e}$ 和溴自由基. 随后, 酰基自由基 $\mathbf{1 b}$ 与 $1 \mathrm{e}$ 反应生成 1f. 最后，中间体 $1 \mathrm{f}$ 释放出炔酮 $1 \mathrm{~g}$ 和自 由基 1c. 同时, 自由基 1c 与溴自由基反应生成中间体 $1 \mathrm{~h}, 1 \mathrm{~h}$ 经过水解生成 BI-OH 完成催化循环 (Scheme 1).

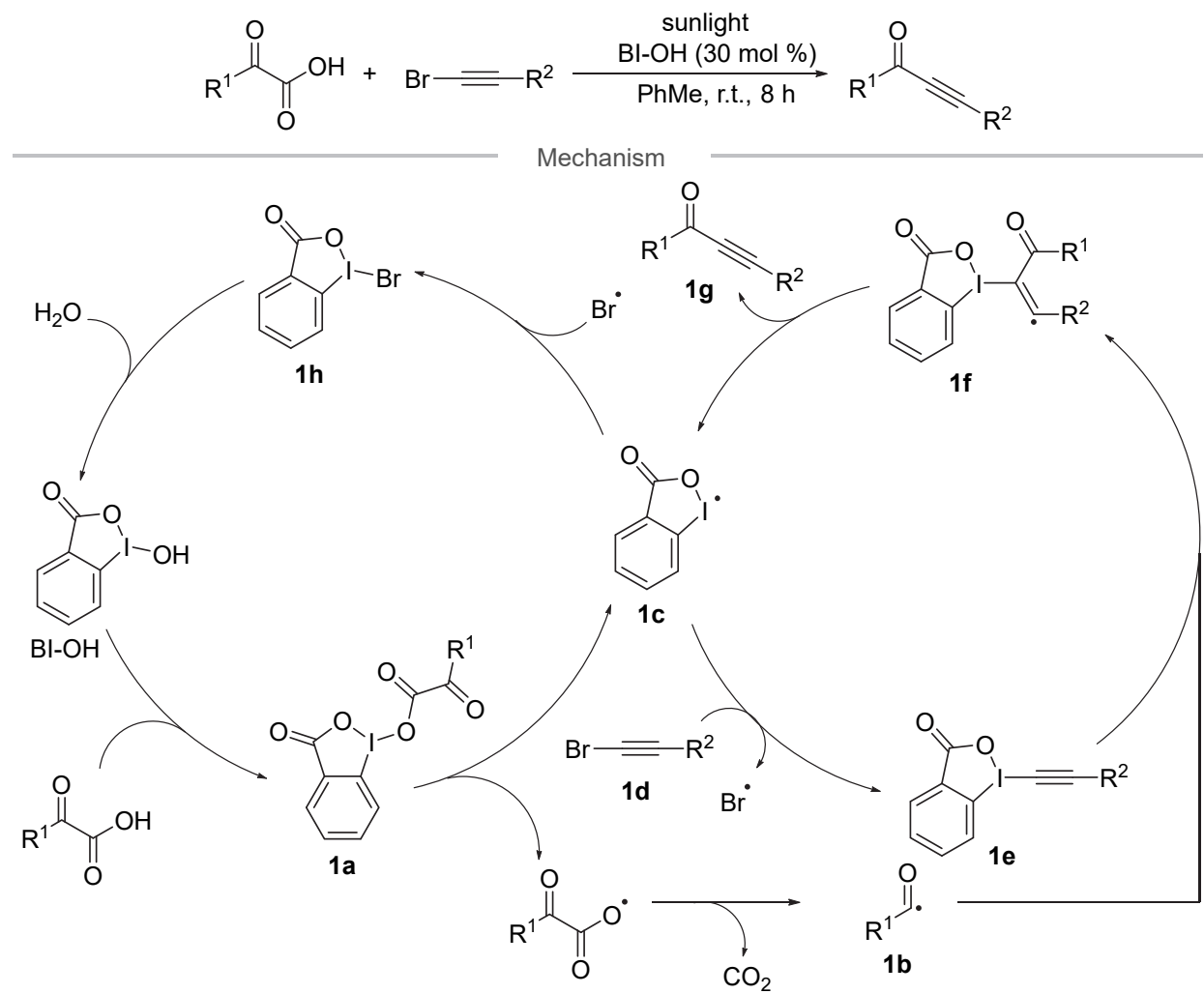

图式 1 日光促进下由炔溴和 $\alpha$-酮酸合成炔酮

Scheme 1 Sunlight-driven synthesis of ynones from $\alpha$-keto acids and bromoacetylenes 
酰基取代的吲哚及其衍生物存在于许多天然产物 及药物分子中, 同时也是各种官能团转化过程中的重要 中间体, 具有较高的研究价值. 合成 C(3)-位酰化吲哚的 经典方法有的 Friedel-Crafts 反应和 Vilsmeier- Haack 反应 等. 2016 年, 王否和李品华课题组 ${ }^{[29]}$ 在绿光照射下以孟 加拉玫瑰红为光催化剂, 实现了吲哚与 $\alpha$-酮酸的脱羧氧 化偶联反应, 合成了 C(3)-位酰化吲哚. 该方法采用廉价 的有机染料为光催化剂, 避免了金属试剂的使用, 而且 使用了低毒的乙醇作溶剂. 更重要的是, 该反应条件温 和, 在室温和空气环境即可顺利进行. 底物拓展实验表 明, 该方法能够兼容各种不同的取代基, 例如脂肪环 $(2 \mathrm{~g})$ 、脂肪链( $2 \mathrm{l})$ 、卤素( $2 \mathrm{c}, 2 \mathrm{i}$ 等)以及给电子基团 $(2 \mathrm{j})$ 和 强吸电子基团(2k)等(Scheme 2).

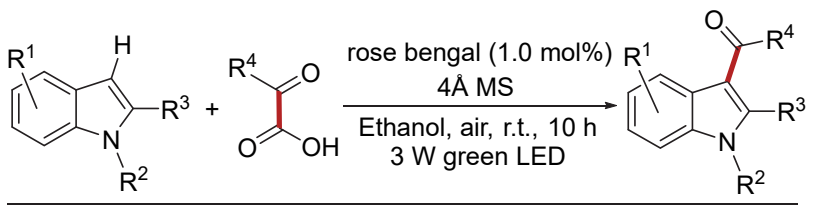

Selected examples<smiles>O=C(c1ccccc1)c1c[nH]c2ccccc12</smiles>

2a, $79 \%$<smiles>O=C(c1ccccc1)c1c[nH]c2cc(Cl)ccc12</smiles>

2d, $85 \%$<smiles>O=C(c1c[nH]c2ccccc12)C1CC1</smiles>

2g, $49 \%$<smiles>O=C(c1ccccc1)c1c[nH]c2ccc(Cl)cc12</smiles>

2b, $85 \%$<smiles>O=C(c1ccccc1)c1c[nH]c2c(Cl)cccc12</smiles>

2e, $59 \%$<smiles>CC(C)(C)c1ccc(C(=O)c2c[nH]c3ccccc23)cc1</smiles>

2h, $50 \%$<smiles>O=C(c1ccccc1)c1c(-c2ccccc2)[nH]c2ccccc12</smiles>

2f, $88 \%$<smiles>O=C(c1ccc(Br)cc1)c1c[nH]c2ccccc12</smiles>

2i, $75 \%$<smiles>COc1ccc(C(=O)c2c[nH]c3ccccc23)cc1</smiles>

2j, $47 \%$<smiles>CC(F)(F)c1ccc(C(=O)c2c[nH]c3ccccc23)cc1</smiles>

2k, $90 \%$

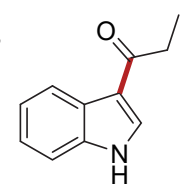

2I, $52 \%$

图式 2 可见光照射下合成 C(3)-位酰化吲哚 Scheme 2 Synthesis of 3-acylindoles under visible light irradiation

在该反应中, 光催化剂孟加拉玫瑰红被可见光活化 进而与氧气作用促使单态氧 $\mathbf{3} \mathbf{a}$ 的产生, $\mathbf{3} \mathbf{a}$ 与 $\alpha$-酮酸作 用后使其脱羧生成相应的酰基自由基 3c. 随后, $3 \mathrm{c}$ 通过 两种不同的反应途径，与吲哚或吲哚自由基正离子发生 自由基加成(Path A 和 Path B). 其中 Path B 中的吲哚自

由基正离子来源于吲哚的单电子氧化. 加成后的中间体 通过氧化和脱质子等步骤生成产物 $\mathrm{C}(3)$-位酰化吲哚 (Scheme 3).

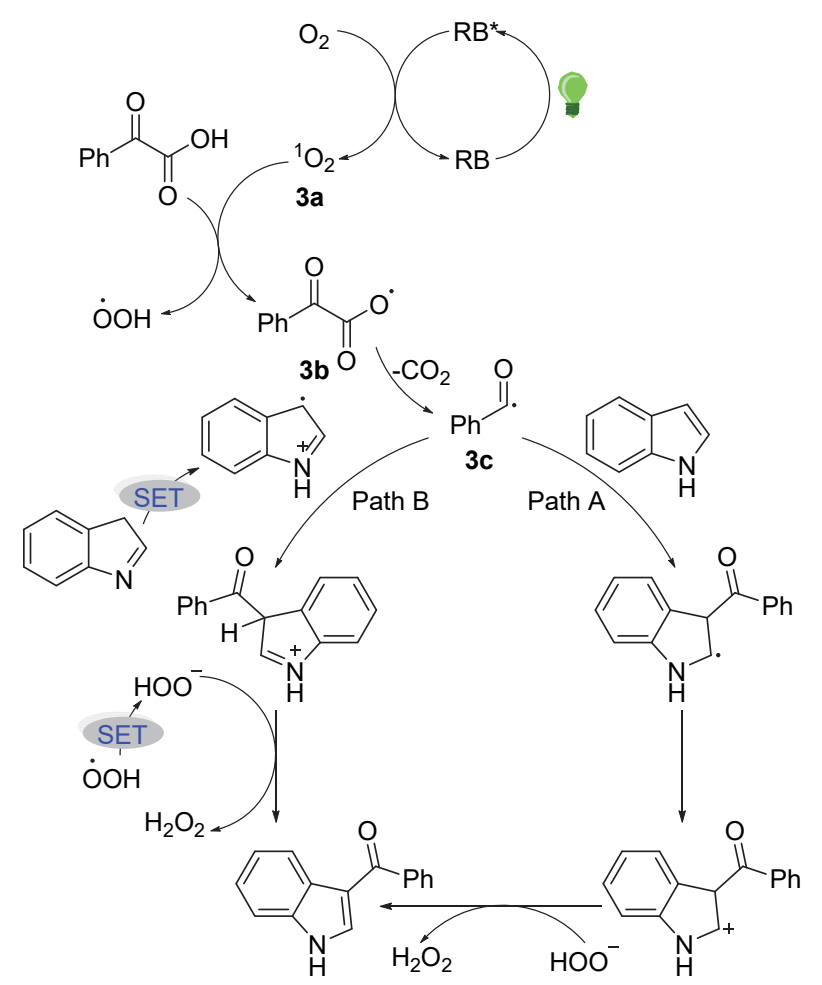

图式 3 合成 C(3)-位酰化吲哚的反应机理

Scheme 3 Mechanism of synthesis of 3-acylindoles

2018 年, Cramail 和 Landais 课题组 ${ }^{[30]}$ 以草氨酸 $4 \mathbf{a}$ 和醇 $4 \mathbf{b}$ 为反应物，2,4,5,6-四(9-咔唑基)-间苯二腈 (4CzIPN)为光催化剂, 高价碘化合物 BI-OAc 为氧化剂, 实现了可见光催化下草氨酸氧化脱羧制备氨基甲酸酯 4c 的方法. 相比较于传统的醇与异氰酸酯反应的制备 方法，该光催化方法避免了异氰酸酯的分离、纯化和储 存等过程，采用一锅煮高效地完成了反应. 该反应不仅 对差基、卤素、炔烃、杂芳烃及酯等多种官能团都具有 较好的兼容性，还有望用于制备聚氨酯，具有较好的应 用前景(Scheme 4).

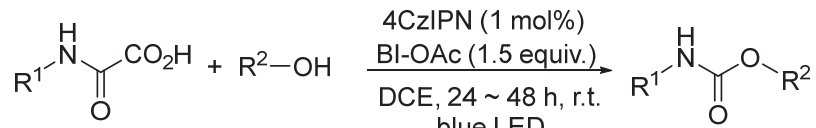

$$
\begin{aligned}
& 4 a \quad 4 b
\end{aligned}
$$

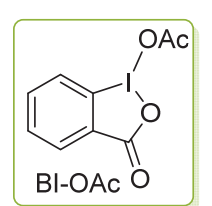

图式 4 可见光催化下草氨酸和醇脱羧偶联制备氨基甲酸酯 Scheme 4 Synthesis of urethanes by photocatalytic decarboxylation coupling of oxamic acids and alcohols 
此外，该方法还可用于非对称嫝的制备. 在完成脱 羧过程后, 通过添加三乙胺(3.0 equiv.)中和 BI-OAc 反应 后产生的苯甲酸, 然后加入伯胺作为反应物, 就能以较 高产率得到目标产物非对称嫝 5a (Scheme 5).

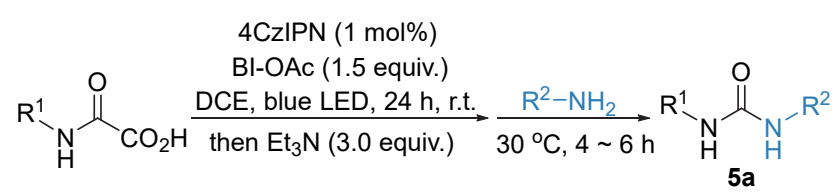

图式 5 可见光催化下合成非对称嫝

Scheme 5 Visible-light photocatalyzed synthesis of unsymmetrical ureas

在该反应中, 光催化剂 $4 \mathrm{CzIPN}$ 在可见光照射下生 成相应的激发态 $\mathrm{PC}^{*}, \mathrm{PC}^{*}$ 与中间体 $\mathbf{6 a}$ 反应产生自由基 6b. 随后, 自由基 $6 \mathrm{~b}$ 通过脱羧过程, 生成氨甲酰自由基 6c, 然后被进一步氧化成相应中间体 6d. 最后, 6d 与醇 或胺反应得到氨基甲酸酯/脲(Scheme 6).

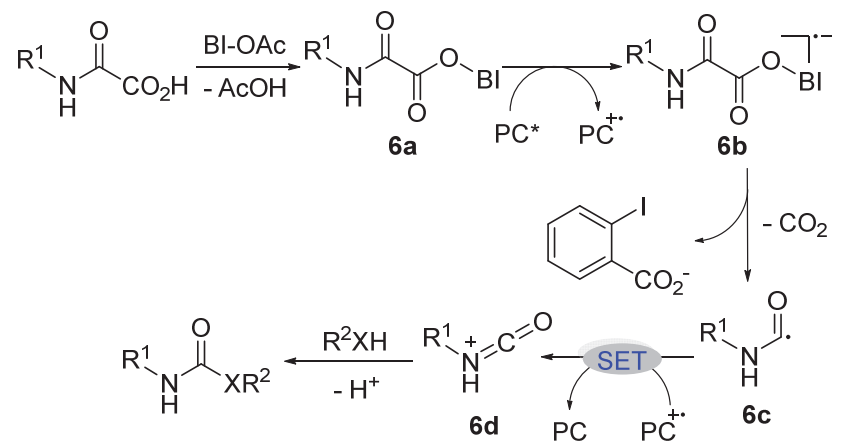

图式 6 可见光催化下草氨酸氧化脱羧反应机理 Scheme 6 Mechanism of visible-light photocatalyzed oxidative decarboxylation of oxamic acids $\alpha$-酮酰胺类化合物是许多具有生物活性的化合物 的关键结构单元. 2019 年, 魏伟课题组 ${ }^{[31]}$ 以孟加拉玫瑰 红为光催化剂, 以 $\alpha$-酮酸、异腈和水为原料, 在可见光 促进下实现了 $\alpha$-䣿酰胺类化合物的合成. 这一方法不仅 操作简单, 而且以空气为氧化剂, 同时还具有反应条件 温和及无金属试剂的优点. 可能的反应机理如 Scheme 7 所示. 首先, 孟加拉玫瑰红(RB)被可见光激发为 $R^{*}$, 然后 $\mathrm{RB}^{*}$ 与 $\alpha$-酮酸 $7 \mathbf{a}$ 经历单电子转移 $(\mathrm{SET})$ 还原成 $\mathrm{RB}^{--}$, $\alpha$-酮酸自身则被氧化为中间体 $7 \mathrm{~b}$. $\mathrm{RB}^{-}$在空气氧化下再 生光催化剂 $\mathrm{RB}$, 并生成超氧自由基阴离子 $\mathrm{O}_{2}^{--} .7 \mathbf{b}$ 在 $\mathrm{O}_{2}^{\circ-}$ 作用下脱羧生成酰基自由基 7c. 随后, 酰基自由基 7c 对异腈加成形成中间体 7d. 最后，中间体 7d 经过 SET 以及与水的亲核反应得到 $\alpha$-酮酰胺类化合物 $7 \mathbf{f}$.

2020 年, 魏伟课题组 ${ }^{[32]}$ 使用有机染料吅啶红作为 光催化剂, 在可见光促进下通过 $\alpha$-酮酸的脱羧反应实现 了喹喔啉-2(1H)-酮的 C(3)位的酰化反应. 这一方法的优 点在于使用廉价易得的吟啶红作为催化剂, 而且利用了 空气中的氧气作为绿色氧化剂, 反应成本较低且清洁绿 色. 以 1-甲基-喹喔啉-2(1H)-酮和苯甲酰甲酸的反应为 例, 在可见光诱导下以鲐啶红(1 mol\%)为催化剂, $\mathrm{C}(3)$ 位酰化产物的产率达 $84 \%$ (Scheme 8).

在可能的反应机理中(Scheme 9), 光催化剂首先接 受光照产生相应的激发态，进一步与氧分子作用生成高 活性的单态氧 9a. 单态氧 9a 促使 $\alpha$-酮酸的氢氧键均裂 然后脱羧生成关键的酰基自由基中间体 9c. 随后，酰基 自由基 9c 对喹喔啉-2(1H)-酮加成, 再经历氢转移、单电 子氧化以及去质子化等步骤生成最终的酰基化产物.
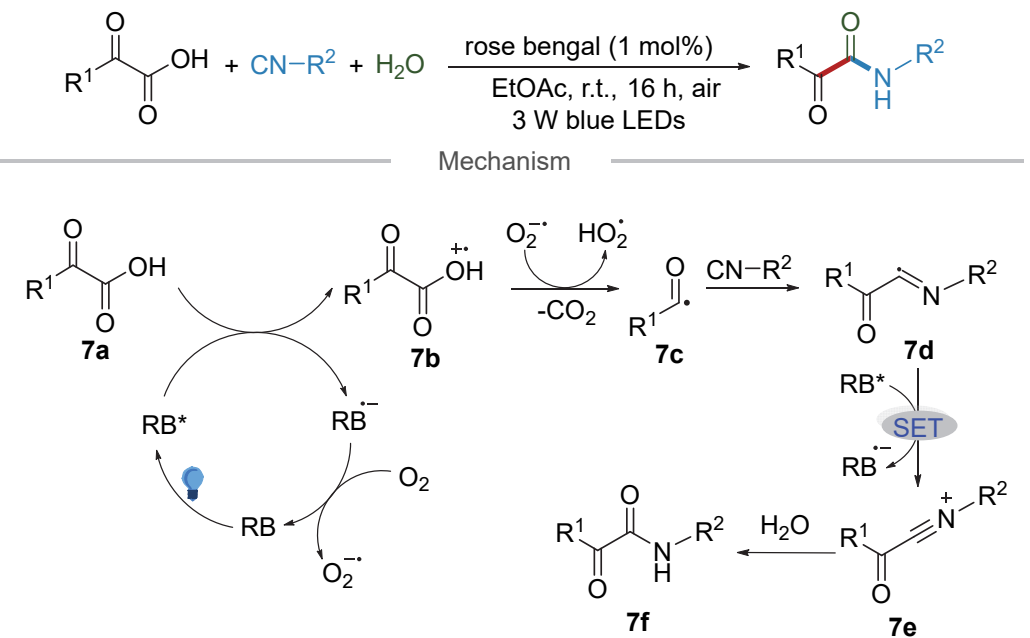

图式 7 可见光促进异腈、 $\alpha$-酮酸和水三组分合成 $\alpha$-酮酰胺

Scheme 7 Synthesis of $\alpha$-ketoamides with isocyanides, $\alpha$-oxocarboxylic acids and water 


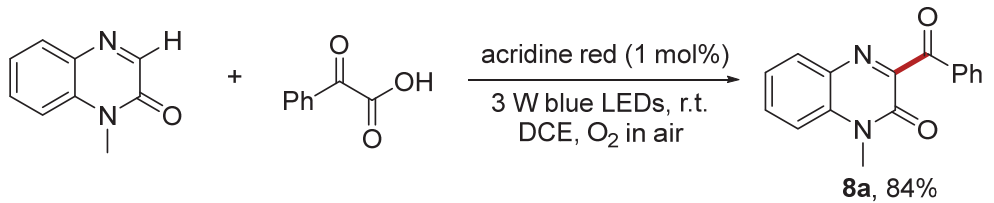

图式 8 可见光促进下合成 C(3)位-酰化喹喔啉-2(1H)-酮

Scheme 8 Visible-light promoted synthesis of 3-acylquinoxaline-2(1H)-ones

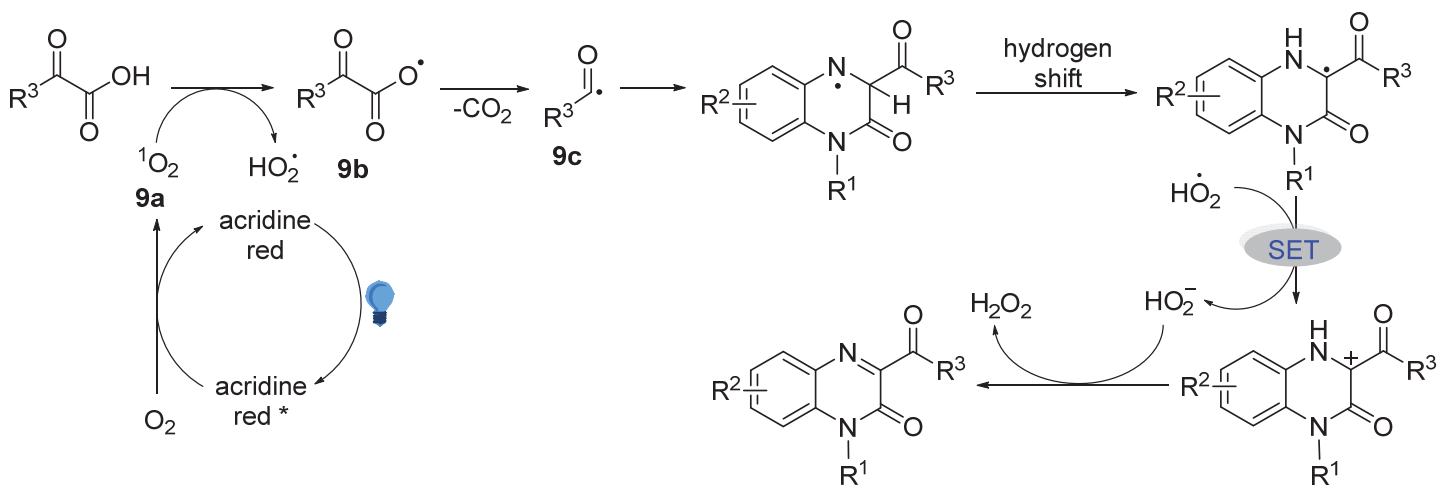

图式 9 合成 C(3)位-酰化喹喔啉-2(1H)-酮的反应机理

Scheme 9 Mechanism of synthesis of 3-acylquinoxaline-2(1H)-ones

偶氮苯作为一类重要的化工原料可作为有机染料、 食品添加剂、光敏材料和生物活性分子等. 2020 年, 霍 聪德课题组 ${ }^{[33]}$ 报道了可见光促进下苯甲酰甲酸对偶氮 苯的氢化酰化反应. 该方法不需要使用任何的催化剂或 添加剂, 同时还具有反应条件温和记底物兼容性良好等 优点. 推测的机理如 Scheme 10: 首先, 偶氮苯 10a 在可 见光的照射下变为激发态 $10 \mathrm{a} *$; 随后, $10 \mathrm{a} *$ 与苯甲酰甲 酸 10b 通过单电子转移生成自由基 10c 和酰基自由基 10d; 紧接着, 自由基 $10 \mathrm{c}$ 与酰基自由基 $10 \mathrm{~d}$ 反应生成中 间体 10e；最后，中间体 10e 经过质子化得到目标产物 $10 f$.

2020 年, 李红喜课题组 ${ }^{[34]}$ 报道了可见光下 $\alpha$-酮酸 与卤代芳烃的交叉偶联反应以及对烯烃的酰化加成反 应. 该反应采用 2-氯噻吨-9-酮(Cl-TXO)为光催化剂代 替了过去方法中成本较高的含 $\mathrm{Ru}$ 或 $\mathrm{Ir}$ 的光催化剂, 同 时也具有反应条件温和、底物范围广等优点.
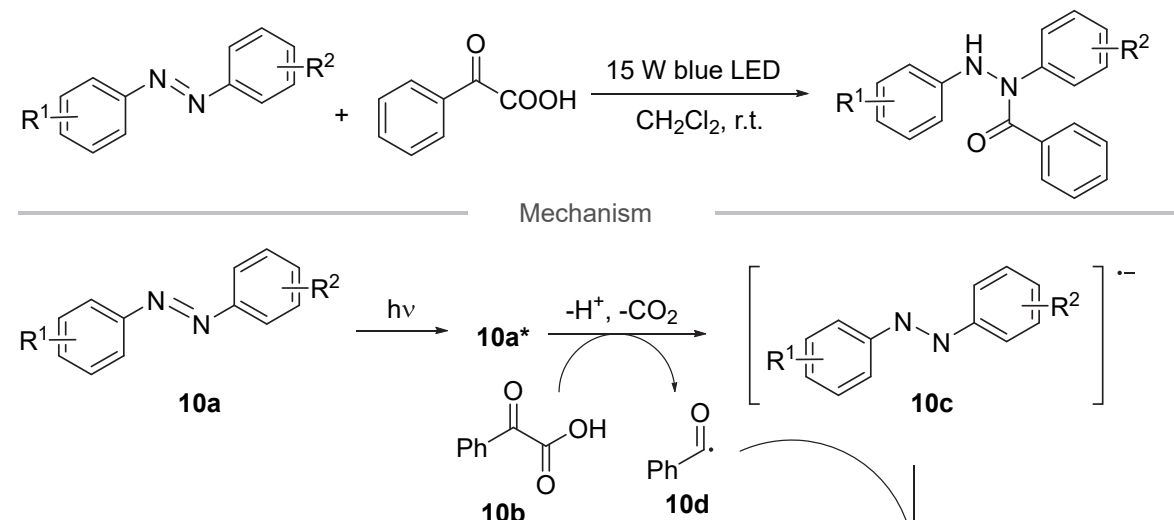<smiles>[R][R]1ccc(N(Nc2c[R1]ccc2)N(C(=O)c2ccccc2)c2ccccc2)cc1</smiles>

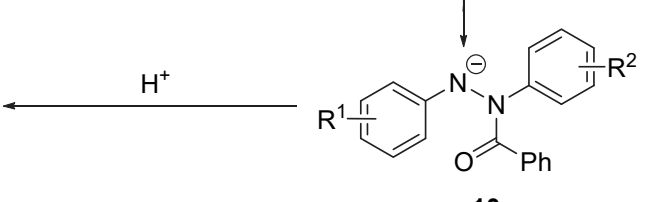

图式 10 可见光促进下 $\alpha$-酮酸对偶氮苯的氢化酰化

Scheme 10 Hydroacylation of azobenzenes by $\alpha$-keto acids under visible-light 
在该反应中, $\alpha$-酮酸 11a 与 Cl-TXO 激发态作用脱羧 生成酰基自由基 $11 b$ 和 $[\mathrm{Cl}-\mathrm{TXO}]^{-}$. 另一方面, $\mathrm{L}_{n} \mathrm{Ni}^{0}$ 与 芳基卤化物 11c 发生氧化加成产生 $\mathrm{L}_{n} \mathrm{Ni}^{\mathrm{II}}(\mathrm{Ar}) \mathrm{X}$. 随后, $\mathrm{L}_{n} \mathrm{Ni}^{\mathrm{II}}(\mathrm{Ar}) \mathrm{X}$ 与酰基自由基 $11 \mathbf{b}$ 反应生成中间体 11d, 还 原消除后生成 $\mathrm{L}_{n} \mathrm{Ni}^{\mathrm{I} X}$ 和目标产物. 最后, $\mathrm{L}_{n} \mathrm{Ni}^{\mathrm{I}} \mathrm{X}$ 和 $[\mathrm{Cl}-\mathrm{TXO}]^{-}$发生单电子转移再生 $\mathrm{L}_{n} \mathrm{Ni}^{0}$ 和 Cl-TXO (Scheme 11).

2018 年, Wencel-Delord 课题组 ${ }^{[35]}$ 以过硫酸钾为氧 化剂, 以乙腈和水为溶剂, 在可见光照射下使 $\alpha$-酮酸发 生脱羧反应实现喹啉 C(4)位酰基化反应. 该反应不需要
添加光敏剂, 且底物适用范围较广 (Scheme 12).

该反应中可能有三种产生途径产生酰基自由基. $\alpha$ 酩酸在可见光下激发, 随后在过硫酸根的作用下直接脱 羧产生酰基自由基(Path A), 同时也可能通过喹啉和 $\alpha$ 酮酸或过硫酸根形成 “电子给体-受体(EDA)” 络合物 13a, 13b (Path B, Path C), EDA 络合物在可见光的作用 下会发生电子跃迁并进入激发态，进而引发自由基反 应，这一过程通常不需要光敏剂的存在. 形成的酰基自 由基后进一步加成喹啉 C(4)位上, 然后经历氢原子转移 和去质子化后得到产物 13c (Scheme 13).

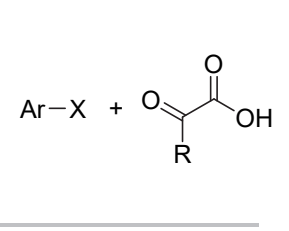

Cl-TXO (20 mol\%)

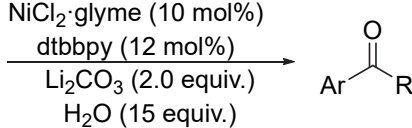

$\mathrm{H}_{2} \mathrm{O}$ (15 equiv.)

45 W CFL, 24 h, DMF

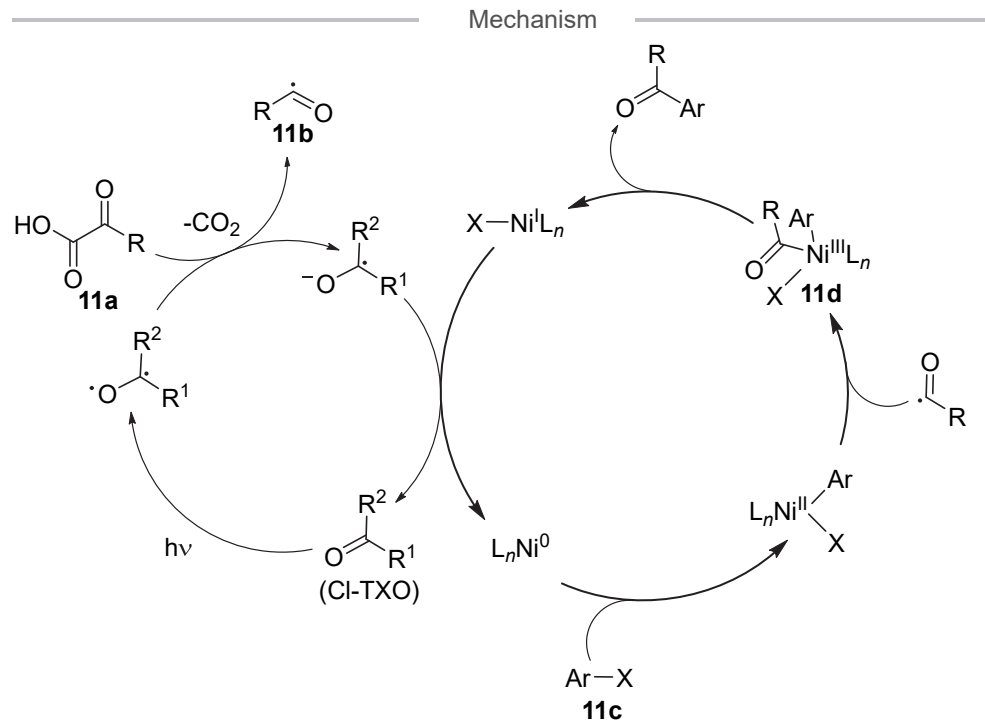

图式 11 可见光促进下 $\alpha$-酮酸与卤代芳烃偶联合成酮

Scheme 11 Visible-light promoted coupling reaction of $\alpha$-keto acids and aromatic halides

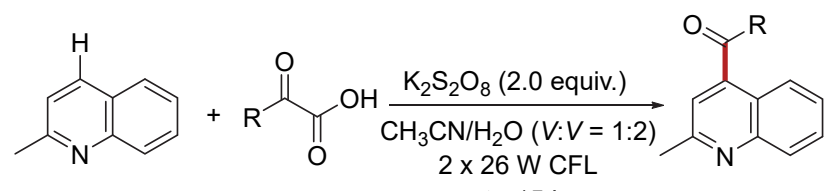
r.t., $15 \mathrm{~h}$<smiles>CCC(=O)c1cc(C)nc2ccccc12</smiles>

图式 12 可见光促进下合成 C(4)-位酰化喹啉

Scheme 12 Visible-light promoted synthesis of C(4)-acyl-quinolines 
Path A

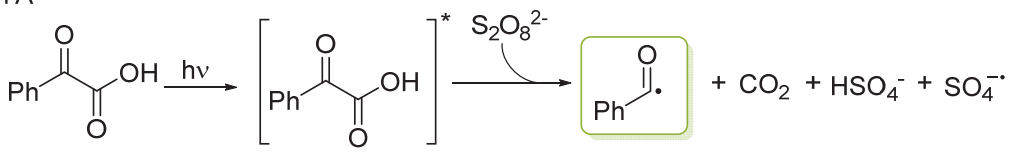

Path B

$$
\mathrm{SO}_{4}^{2-}+\mathrm{SO}_{4}^{-*}+\mathrm{CO}_{2}+\underbrace{}_{\mathrm{EDA} \text { complex }}
$$

Path C

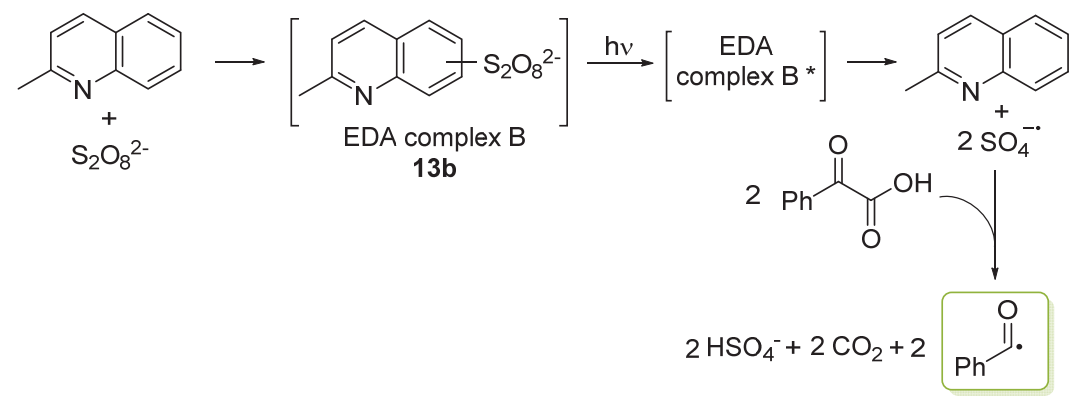

Radical functionalization

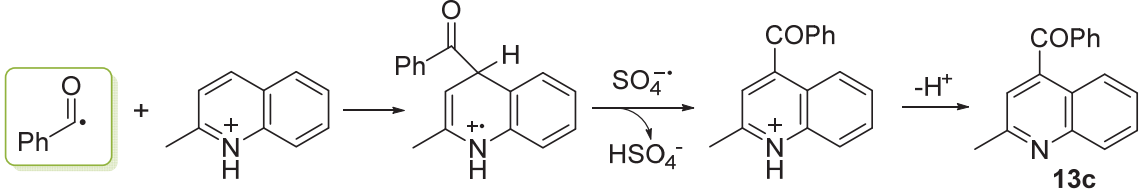

图式 13 可见光下合成 C(4)-位酰化喹啉的反应机理

Scheme 13 Mechanism of synthesis of 4-acylquinoline under visible-light

2018 年张博课题组 ${ }^{[36]}$ 在可见光照射下以双三氟乙 酰碘苯(PIFA)作为氧化剂, 实现了氮杂环与 $\alpha$-酮酸的脱 羧酰化反应. 以苯甲酰甲酸为反应物, 可以较高收率实 现喹啉、异喹啉、菲啶及苯并噻唑等含氮杂环的苯甲酰 化反应. 紫外可见光吸收光谱表明该反应过程中没有产 生 EDA 络合物. PIFA 首先与 $\alpha$-酮酸作用并在可见光的 作用下发生均裂而产生自由基中间体, 进一步脱羧后生 成的酰基自由基与氮杂环作用实现酰基化反应(Scheme 14).

2020 年, 何卫民课题组 ${ }^{[37]}$ 以空气为氧化剂, 二氯乙 烷和水为溶剂, 在可见光下实现了喹喔啉-2(1H)-酤 C(3) 位的酰化反应. 该反应能够较好地兼容常见的基团如卤 素(15b, 15i)、芳香杂环 $(15 \mathrm{c})$ 、烯基、炔基(15e)和苯基 (15d)等. 同时, 该方法仅使用空气中的氧气为氧化剂, 无需其他的强氧化剂、金属催化剂或外加光敏剂, 极大 地减少了污染物的产生 ${ }^{[38]}$ (Scheme 15).

在可能的反应机理中(Scheme 16), 喹喔啉酮底物 首先在可见光的照射下产生激发态, 与空气中的氧分子

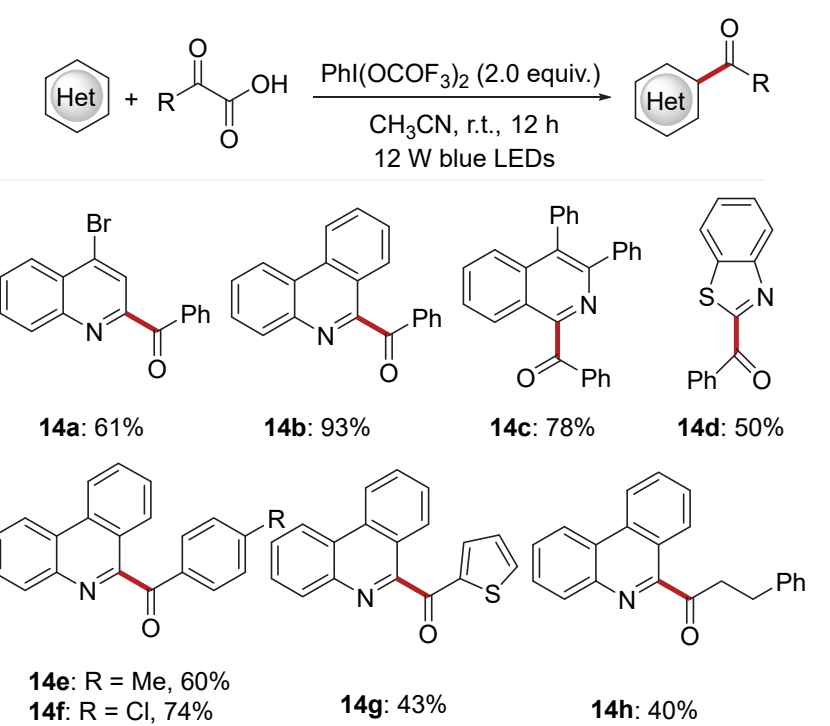

图式 14 可见光下氮杂环与 $\alpha$-酮酸的脱羧酰化反应 Scheme 14 Visible light-induced decarboxylative acylation of $\mathrm{N}$-heterocycles and $\alpha$-keto acids 


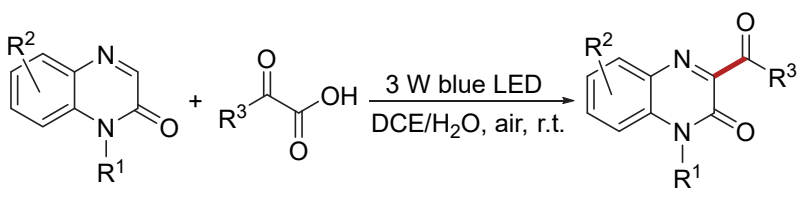

Selected examples<smiles>Cn1c(=O)c(C(=O)c2ccccc2)nc2ccccc21</smiles>

15a, $87 \%$<smiles>O=C(c1ccccc1)c1nc2ccccc2[nH]c1=O</smiles>

$\mathrm{Ph}$<smiles>Cn1c(=O)c(C(=O)c2ccccc2)nc2cc(Cl)ccc21</smiles>

15b, $79 \%$<smiles>C#CCn1c(=O)c(C(=O)c2ccccc2)nc2ccccc21</smiles>

$15 d, 89 \%$

15e, $77 \%$<smiles>Cn1c(=O)c(C(=O)c2cccc3ccccc23)nc2ccccc21</smiles>

15g, $67 \%$<smiles>CC(=O)c1nc2ccccc2n(C)c1=O</smiles>

15h, 36\%<smiles>Cn1c(=O)c(C(=O)c2cccs2)nc2ccccc21</smiles>

15c, $61 \%$
图式 15 可见光诱导下喹喔啉-2(1H)-酮的无光敏剂酰化反应 Scheme 15 Visible-light-induced acylation of quinoxalin2(1H)-ones without photocatalyst

进一步作用后生成活泼的单态氧. 随后， $\alpha$-酮酸与单态 氧间发生氢原子转移过程，生成酰基自由基、二氧化碳 和过氧化羟基自由基. 酰基自由基随后对喹喔啉 -2(1H)-酮 C(3)位加成, 形成中间体 16a. 中间体 16a 会 发生分子内的氢迁移过程，生成中间体 $16 \mathrm{~b}$. 最后，中 间体 $16 \mathrm{~b}$ 与过氧化差基自由基作用生成产物和过氧化氢 分子. 值得注意的是, 反应产物 $\mathrm{C}(3)$-位酰化喹喔啉 -2(1H)-酮同样能够在该过程中作为光催化剂, 促进反应 进行.

\section{$2 \alpha$-酮酸在环化反应中的应用}

杂环分子, 尤其是含氮杂环化合物, 是有机合成中 非常重要的骨架, 往往具有潜在生物活性或者药理活 性. 因此, 开发新型的合成方法高效构筑多种杂环骨架 是有机合成工作者长期以来的目标 ${ }^{[39-47] .2020}$ 年, Sharma 课题组 ${ }^{[88]}$ 以 1,4 -二氧六环和水为溶剂, 过氧化氢 为氧化剂, 在可见光照射下实现了 2 -氨基苯硫酚和 $\alpha$-酮 酸的脱羒偶联反应合成苯并噻唑类化合物. 该反应中以 过氧化氢作为氧化剂, 但空气中的氧气仍对反应有促进 作用. 以苯甲酰甲酸和 2-氨基苯硫酚的反应为例, 在标 准条件下反应 $8 \mathrm{~h}$, 产物苯并噻唑的收率达 $88 \%$ (17a). 底物拓展实验表明, 该反应可兼容各种取代基, 如卤素

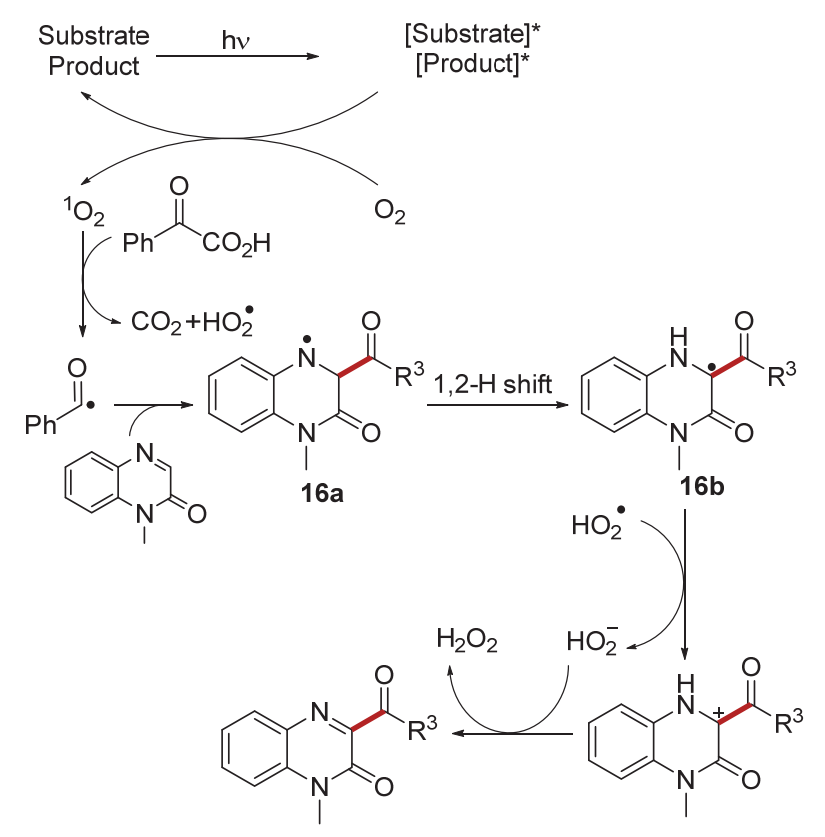

图式 16 可见光下喹喔啉-2(1H)-酮的酰化反应机理 Scheme 16 Mechanism of acylation of quinoxalin-2(1H)-ones under visible-light

(17b)、羟基 $(17 c)$ 、甲氧基 $(17 e)$ 以及杂环 $(17 f)$ 等，以中等 至良好的收率得到相应的产物 (48\% 73\%) (Scheme 17).

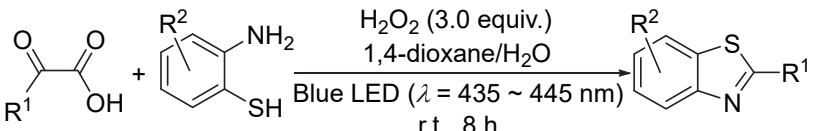

Selected examples

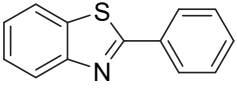

17a: $88 \%$<smiles>Oc1ccccc1-c1nc2cc(C(F)(F)F)ccc2s1</smiles>

17c: $48 \%$

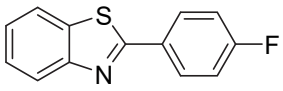

17b: $73 \%$

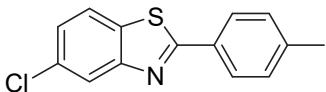

17d: $62 \%$

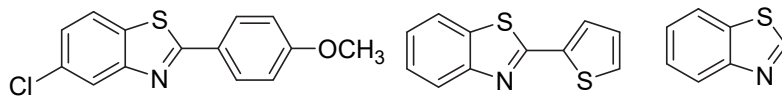

17f: $82 \% \quad \mathbf{1 7 g}: 40 \%$

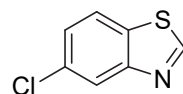

17h: $61 \%$

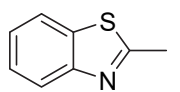

17i: $53 \%$

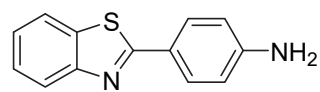

17j: n.d.
图式 17 可见光诱导下由 2-氨基苯硫酚和 $\alpha$-酮酸合成苯并噻 唑

Scheme 17 Visible-light-induced synthesis of benzothiazoles from $\alpha$-keto acids and 2-aminothiophenol

在可能的反应机理中, $18 \mathrm{a}$ 首先与 $\mathbf{1 8 b}$ 反应生成 EDA 络合物，随后在可见光的激发下产生瞬态中间体 
18c. $18 \mathrm{c}$ 脱去一分子水后形成 $18 \mathrm{~d}$. 随后, $18 \mathrm{~d}$ 与过氧化 氢反应生成中间体 $18 \mathrm{e}$. 18e 经历脱羧和氢原子转移 (HAT), 从而转变为中间体 18f, $18 \mathrm{f}$ 进一步与过氧化羟基 自由基作用产生 $18 \mathrm{~g}$. 最后 $18 \mathrm{~g}$ 经过分子内的自由基偶联 反应得到苯并噻唑类产物 18j (Scheme 18).
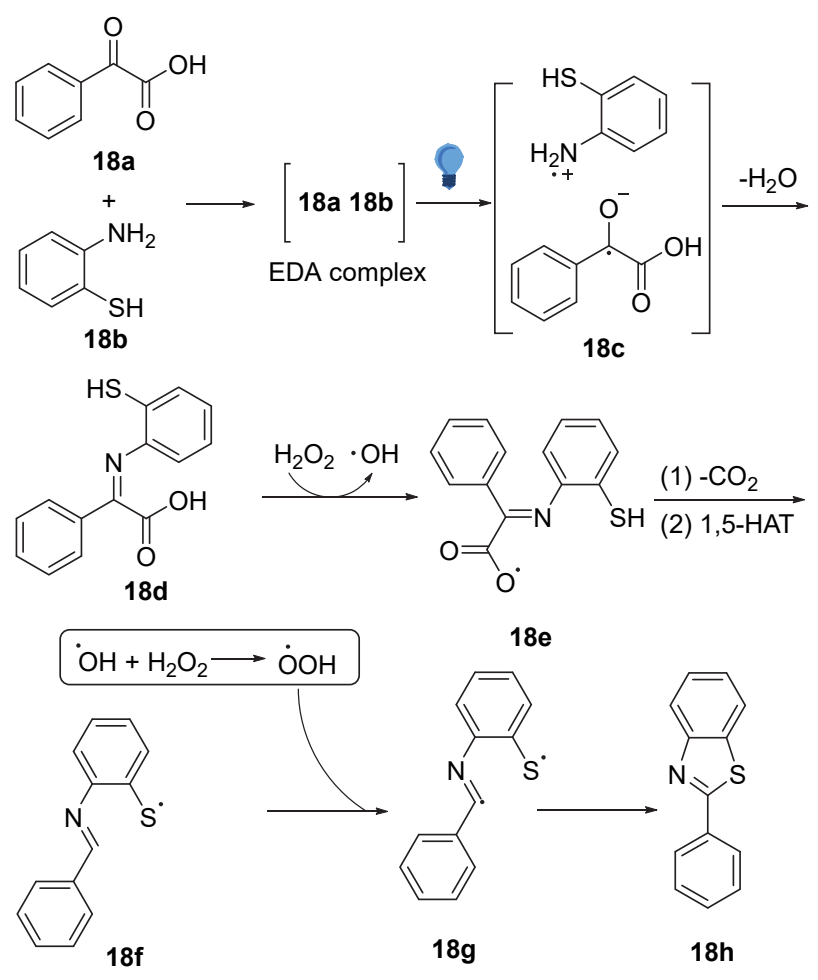

图式 18 可见光诱导下合成苯并噻唑的机理

Scheme 18 Mechanism of visible-light-induced synthesis of benzothiazoles

异喹啉 1,3- $(2 H, 4 H)$ 二酮骨架是许多具有生物活性 的化合物的重要结构单元. 因此, 开发简便高效的方法 来合成异喹啉 1,3- $(2 H, 4 H)$ 二酮及其衍生物具有重要意 义. 2020 年, 胡雨来等 ${ }^{[49]}$ 以曙红 $B$ 为光催化剂, $\left(\mathrm{NH}_{4}\right)_{2} \mathrm{~S}_{2} \mathrm{O}_{8}$ 为氧化剂, 二甲亚砜为溶剂, 在蓝光促进下 实现了 $N$-甲基丙烯酰基- $N$-甲基苯甲酰胺和 $\alpha$-酮酸的串 联环化反应合成异喹啉 1,3-(2H,4H)二酮类化合物。该 反应在克级实验 $(5 \mathrm{mmol})$ 中产率达 $81 \%$, 具有潜在的应 用价值(Scheme 19).

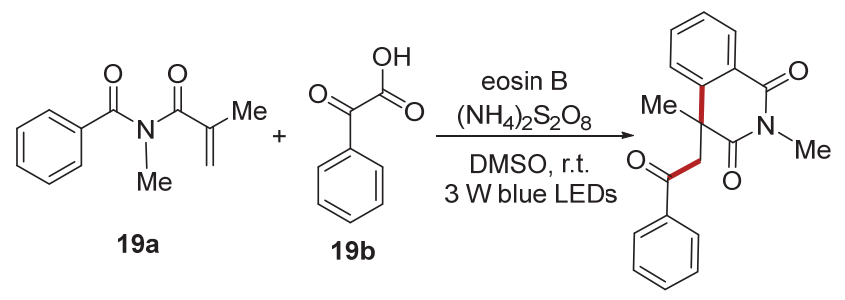

图式 19 可见光促进下合成异喹啉 1,3- $(2 H, 4 H)$ 二酮 Scheme 19 Visible light-promoted synthesis of isoquinoline1,3(2H,4H)-dione
在该反应中, 光催化剂曙红 B (eosin B) 首先在可见 光照射下被激发为 $\operatorname{eosin} \mathrm{B}^{*}$. eosin $\mathrm{B}$ *进一步与过硫酸根 发生 SET 作用, 将过硫酸根还原为相应的自由基负离子 20b. 随后, 20b 与 $\alpha$-酮酸反应脱羧得到酰基自由基 $20 \mathrm{c}$ (Path A). 此外, $\alpha$-酮酸也可能在可见光照射下与过硫酸 根作用发生脱羧得到 20c (Path B). 20c 进一步加成到的 苯酰胺 $20 \mathrm{~d}$ 的碳一碳双键上, 最后经历环化、单电子转移 及去质子化后得到异喹啉 1,3- $(2 H, 4 H)$ 二酮类产物 (Scheme 20).

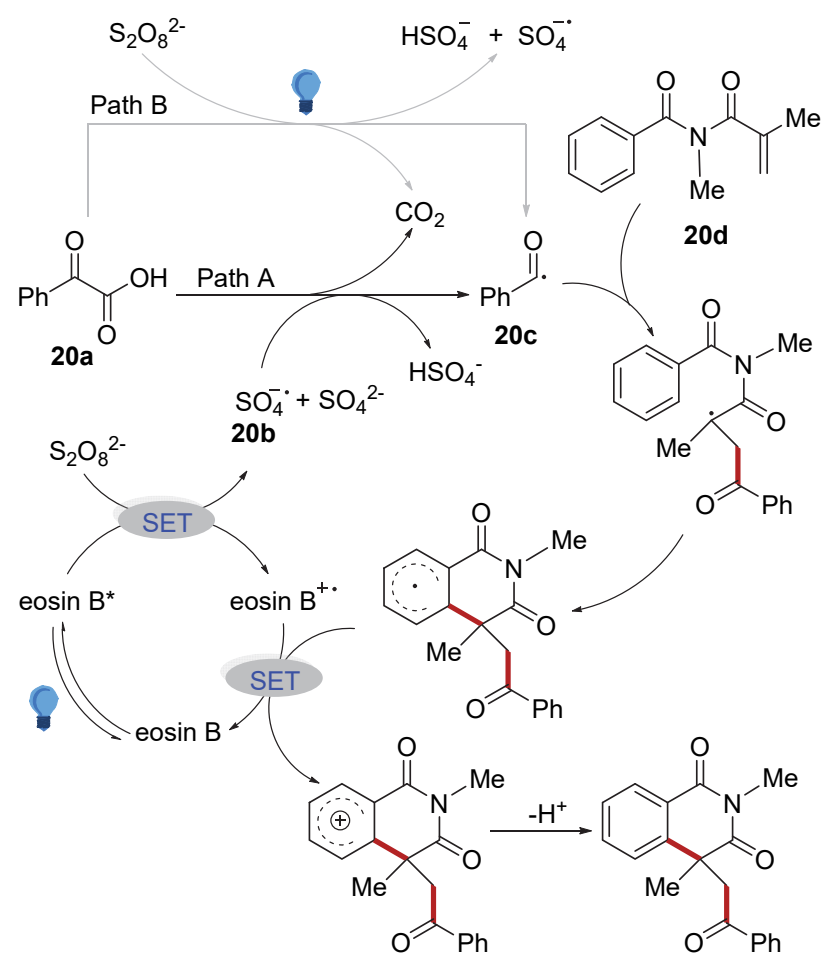

图式 20 合成异喹啉 1,3-(2H,4H)二酮的反应机理 Scheme 20 Mechanism of synthesis of isoquinoline-1,3$(2 H, 4 H)$-dione

最近，陈晓岗和於兵课题组 ${ }^{[50]}$ 在可见光诱导下以 4 CzIPN 为光催化剂, 实现了 $\alpha$-酮酸与多种杂环的脱羧 酰化环化反应. 例如, 以碳酸二甲酯(DMC)为绿色溶剂, 空气中的氧气为氧化剂, $\alpha$-酩酸和 $N$-丙烯酰基- 2-苯基 苯并咪唑/吲哚 21a 在光照下反应, 可生成环化产物苯并 咪唑/吲哚[2,1- $a$ ]异喹啉-6(5H)-酮 21b. 除了应用于环化 反应外, 该反应也适用于一些常见的杂环的酰化, 例如 喹诺酮、异喹啉、喹喔啉酮和苯并二氢呋喃-4-酮等. 若 以乙腈为溶剂, 过氧化二苯甲酰(BPO)为氧化剂, 该催 化体系还可用于合成硫代黄酮 21d 和氮杂螺[4.5] 三烯酮 21f. 总体而言, 该催化体系条件温和, 无需添加额外的 金属试剂和碱, 底物适用范围宽泛, 具有较高的合成应 用价值(Scheme 21). 


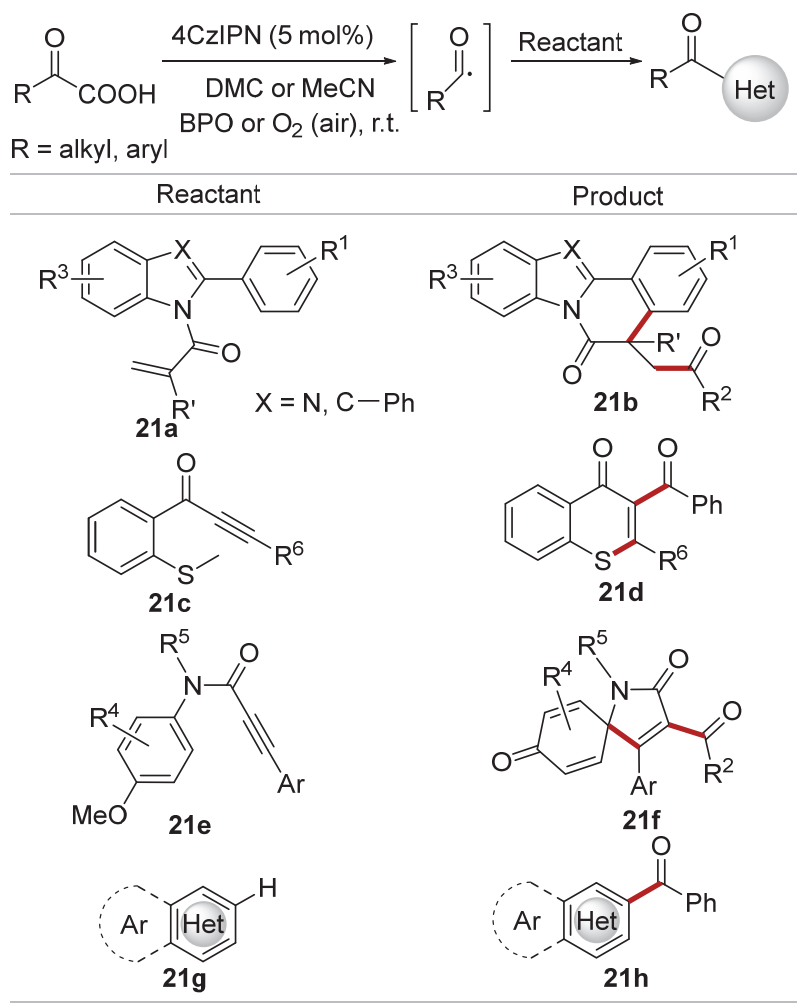

图式 21 可见光下 4CzIPN 催化的无金属杂环酰化反应 Scheme 21 Metal-free acylation of heterocycles catalyzed by $4 \mathrm{CzIPN}$ under visible-light
以 $\alpha$-酮酸和 $N$-丙烯酰基-2-苯基苯并咪唑的反应为 例, 在可能的反应机理中(Scheme 22), $4 \mathrm{CzIPN}$ 首先被可 见光激发为 $4 \mathrm{CzIPN}^{*}$. 随后 $4 \mathrm{CzIPN}^{*}$ 与 $\alpha$-酮酸 22a 经历 SET 过程, 产生 $4 \mathrm{CzIPN}^{-}$和酰基自由基 $\mathbf{2 2 b}$. 酰基自由 基对反应物种 22c 的碳-碳双键/参键发生加成, 进一步 发生分子内环化、单电子转移及去质子化等步骤，得到 相应的酰化环化产物.

2016 年, 王磊课题组 ${ }^{[51]}$ 以 $N$-芳基丙烯酰胺 23a 和 $\alpha$-酮酸 23b 为原料, BI-OAc 为氧化剂, 实现了可见光下 $N$-芳基丙烯酰胺的脱羧酰化-芳化反应，合成了含羰基 的氧化吲哚类化合物. 该反应无需添加光敏剂, 仅采用 催化量的高价碘试剂为催化剂, 且副产物只有二氧化碳 和氢气(Scheme 23)

在该反应中, $\alpha$-酮酸首先与 BI-OAc 发生酯交换, 生 成中间体 24a, 中间体 24a 进一步脱羧产生酰基自由基 和碘苯自由基. 随后酰基自由基对 $N$-芳基丙烯酰胺加 成，再经历分子内的自由基环化过程后生成中间体 $\mathbf{2 4 b}$. 最后，中间体 24b 在碘苯自由基作用下脱氢生成产物， 同时重新生成活性催化物种 BI-H 进入下一次循环 (Scheme 24).

2021 年, 王否课题组 ${ }^{[52]}$ 以 $\alpha$-酮酸 $25 \mathbf{a}$ 和二芳基乙炔 25b 为原料, 1,1,2-三氯乙烷为溶剂, 在紫外 $(365 \mathrm{~nm})$ 或

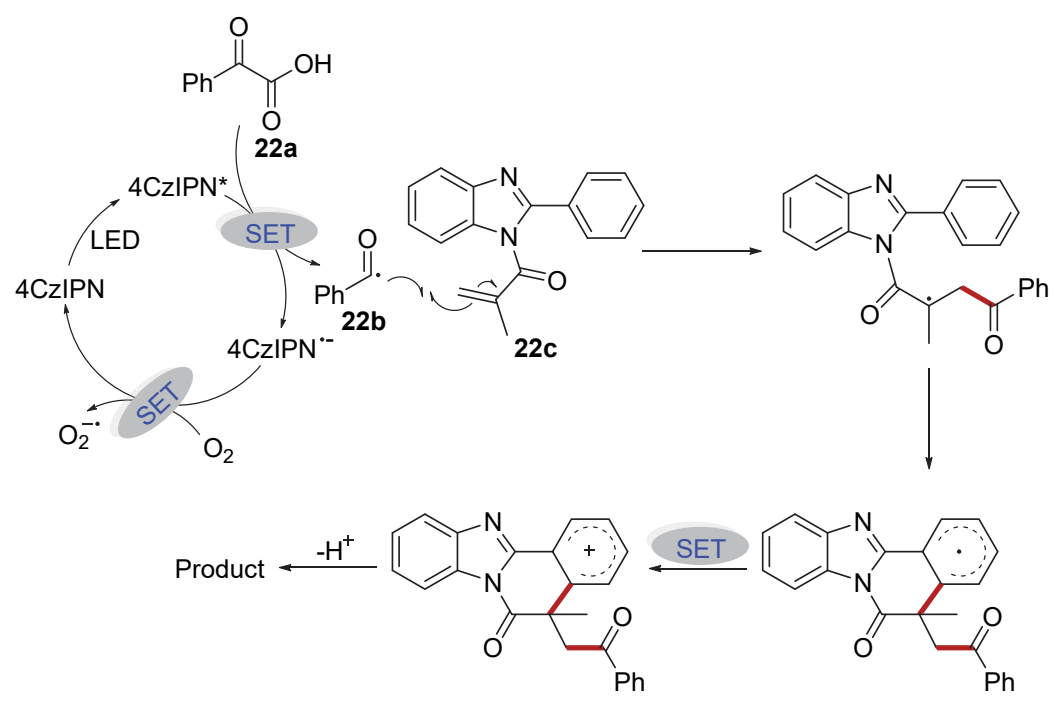

图式 $224 \mathrm{CzIPN}$ 催化的酰化/环化反应机理

Scheme 22 Mechanism of acylation/cyclization catalyzed by 4CzIPN

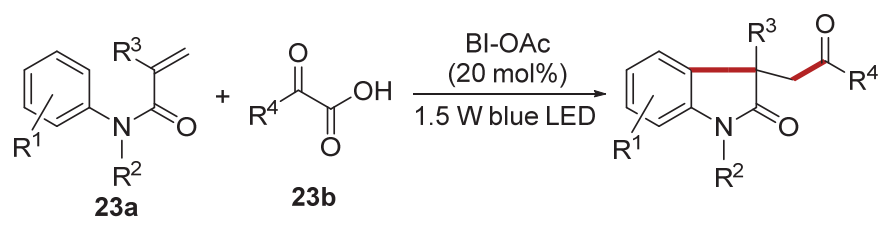

图式 23 可见光下无光敏剂合成氧化吲哚类化合物

Scheme 23 Synthesis of oxindoles under visible light without photosensitizer 


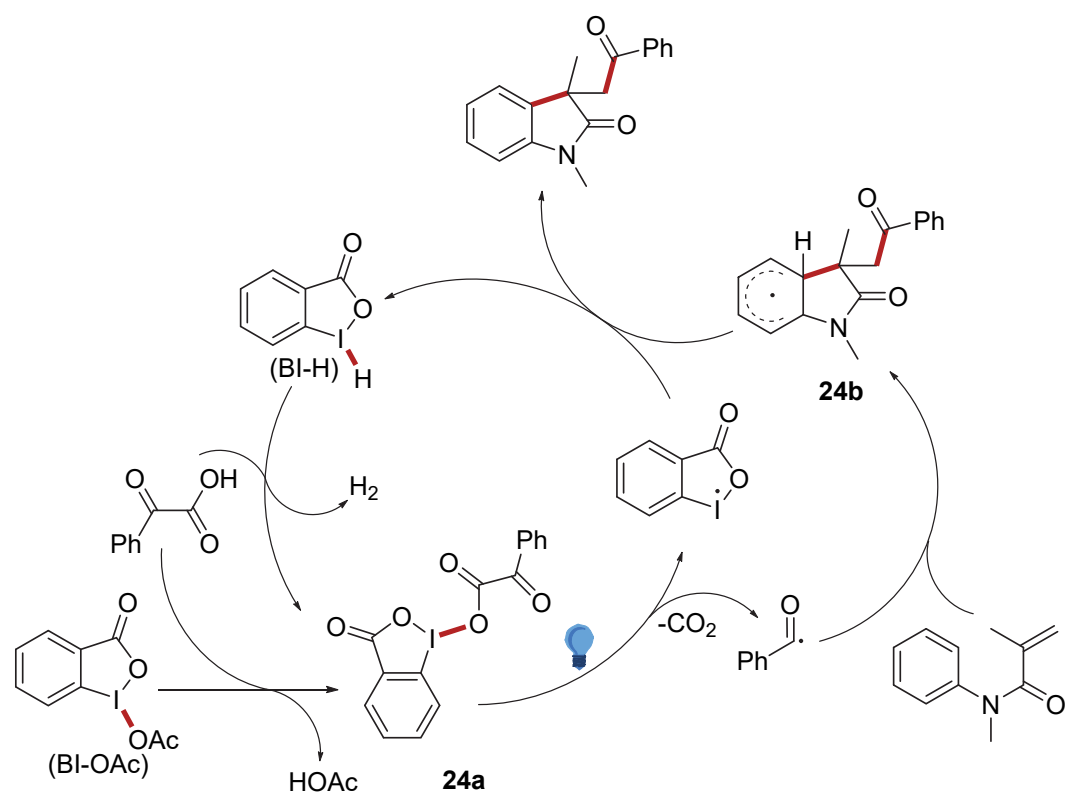

图式 24 可见光下合成差弪吲哚类化合物的机理

Scheme 24 Mechanism of synthesis of oxindoles under visible light

可见光(420 $\mathrm{nm}$ 光照下)下合成了 3-羟基菲-[9,10-c]并呋 喃-1(3H)-酮及其衍生物 25c. 该方法未使用金属催化剂 或额外的添加剂, 且唯一的副产物为氢气, 反应条件温 和且绿色高效(Scheme 25).

该反应的机理如 Scheme $26, \alpha$-酮酸的氢氧键首先 在紫外或可见光的照射下均裂，生成自由基 26a. 该自 由基进一步加成到二芳基乙炔的碳-碳参键上, 形成活
性中间体 26b. 随后中间体 26b 发生分子内环化, 再与 氢原子结合后得到中间体 26c. 中间体 26c 经历质子化 和脱水过程得到中间体 26d. 中间体 26d 会进一步共振 为结构 26e, 结构 26e 经历与水的亲核加成/去质子化后 生成中间体 26f，中间体 $26 \mathbf{f}$ 最后在光照下放氢生成最终 产物.<smiles>O=C(O)C(=O)c1ccccc1</smiles>

25a

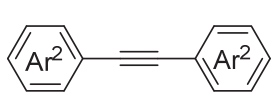

$25 b$<smiles>O=C1OC(O)(c2ccccc2)c2c1c1ccccc1c1ccccc21</smiles>

$25 \mathrm{c}$

图式 25 光化学合成 3-羟基菲-[9,10-c]并呋喃-1(3H)-酮及其衍生物

Scheme 25 Photochemical synthesis of 3-hydroxyphenanthro[9,10-c]furan-1(3H)-ones and its derivatives

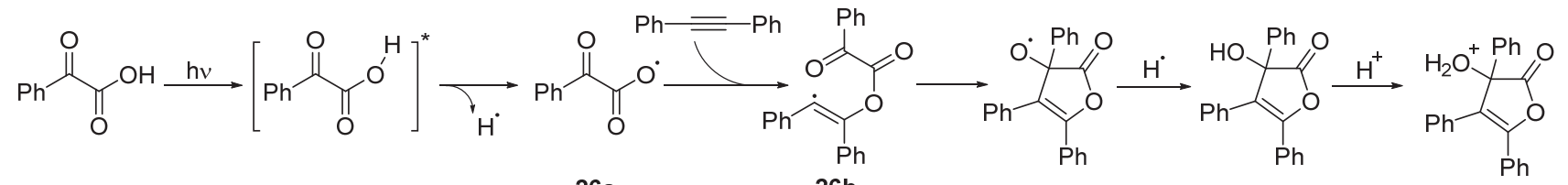

26a

26b 26c

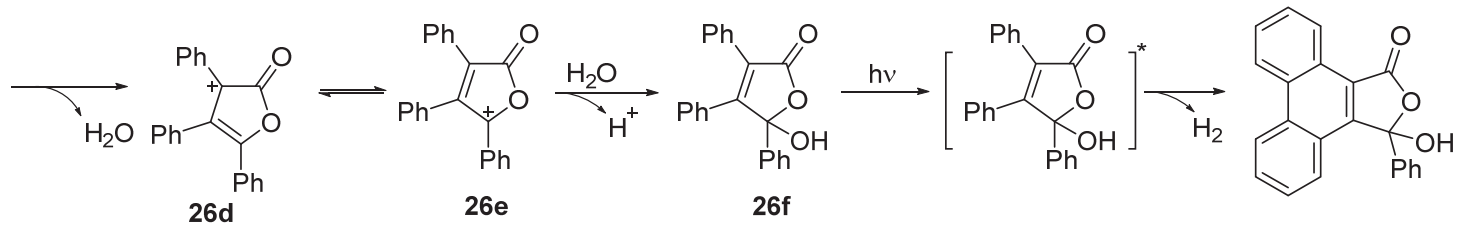

图式 26 光化学合成 3-羟基菲-[9,10-c]并呋喃-1(3H)-酮的机理

Scheme 26 Mechanism of photochemical synthesis of 3-hydroxyphenanthro[9,10-c]furan-1(3H)-ones 


\section{$3 \alpha$-酮酸在其他反应中的应用}

2017 年, 段新华课题组 ${ }^{[53]}$ 以罗丹明 B 为光催化剂, $\mathrm{BI}-\mathrm{OH}$ 为氧化剂, 在可见光催化下实现了乙烯基环丁醇 与 $\alpha$-酮酸的无金属氧化脱羧酰化/扩环反应，合成了 $1,4-$ 二羰基化合物. 该反应条件温和, 而且能够很好地兼容 各种不同的取代基如卤素、三氟甲基和叔丁基等. 在该 反应中, 光催化剂 $(\mathrm{PC})$ 首先在可见光的照射下变为激发 态 PC*，同时， $\alpha$-酮酸 $27 \mathbf{a}$ 与 BI-OH 反应生成中间体 $\mathbf{2 7 b}$. 27b 进一步与 $\mathrm{PC}^{*}$ 作用, 发生脱羧生成酰基自由基 $27 \mathrm{c}$ 和苯碘酰正离子 $\mathrm{BI}^{+}$. 随后, 酰基自由基 $27 \mathrm{c}$ 对乙烯基 环丁醇的碳一碳双键加成, 经 $\mathrm{BI}^{+}$氧化后形成对应的中 间体 27e. 中间体 27e 再经历 1,2-烷基迁移后生成目标产 物 27f. 最后, $\mathrm{PC}$ - - 被苯碘酰自由基 $\mathrm{BI}$ •氧化, 实现光催化 剂的再生(Scheme 27).
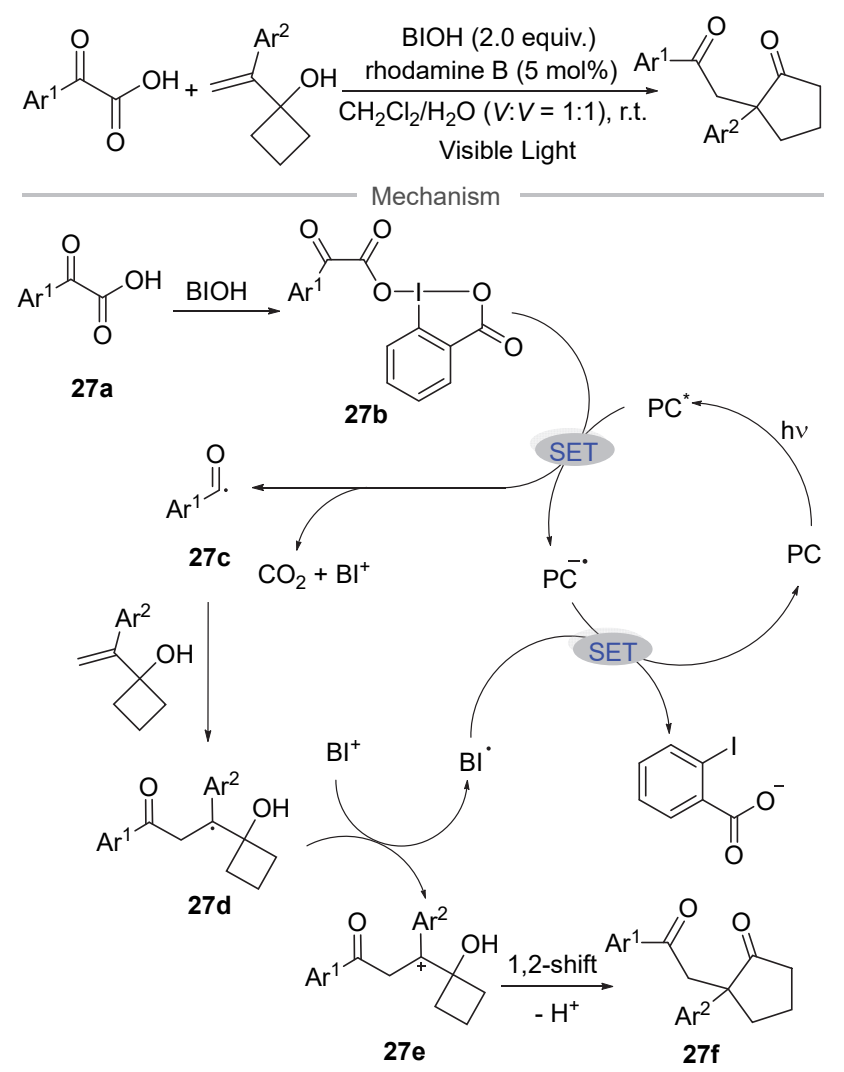

图式 27 可见光催化下由乙烯基环丁醇与 $\alpha$-酮酸合成 1,4-二 羰基化合物

Scheme 27 Visible-light-catalyzed synthesis of 1,4-dicarbonyl compounds from vinylcyclobutanols and $\alpha$-keto acids

2019 年 Landais 课题组 ${ }^{[54]}$ 以草氨酸 28a 为反应物, $4 \mathrm{CzIPN}$ 为光催化剂, BI-OAc 为氧化剂, 实现了可见光 促进下杂环的酰胺化反应. 该反应条件温和, 同时对带 不同取代基如金刚烷、酰胺及芳环的草氨酸都有良好的 兼容性, 并且广泛适用于喹啉、苯并噻唑和喹喔啉等多 种杂环(Scheme 28).

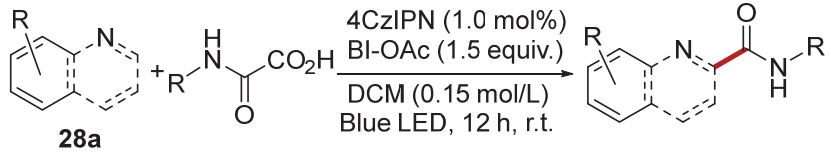

图式 28 可见光促进下草氨酸对氮杂环的自由基加成反应 Scheme 28 Visible light-promoted radical addition of oxamic acids to N-heterocycles

值得注意的是，该方法还能用于构筑手性酰胺. 首 先由 $L$-氨基酸制得相应的草氨酸, 其进一步与杂环反应 后得到对应的手性酰胺产物. 该反应过程不会产生对映 异构体, 且产物构型具有较好的稳定性(Scheme 29).
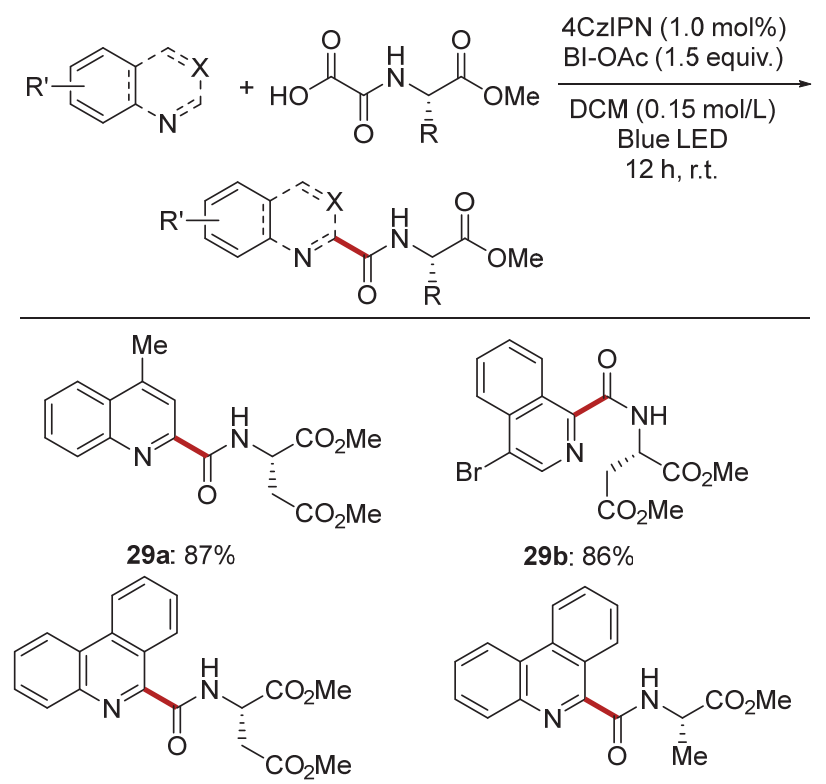

29b: $86 \%$

29c: $89 \%$<smiles>CC(=O)C(C)NC(=O)c1nc2ccccc2c2ccccc12</smiles>

29d: $91 \%$<smiles>CC(=O)C(C)NC(=O)c1nc2ccccc2nc1Cl</smiles>

29e: $69 \%$<smiles>CC(=O)C(C)NC(=O)c1nccc2c(C#N)cccc12</smiles>

29f: $74 \%$

图式 29 由草氨酸和含氮杂环合成手性酰胺

Scheme 29 Synthesis of chiral amides with oxamic acids and $\mathrm{N}$-heterocycles compounds

\section{4 总结与展望}

可见光诱导的有机反应由于条件温和及操作简便, 已经成为当前有机合成领域的研究热点. 在可见光照射 下，曙红 B、罗丹明 B 和孟加拉玫瑰红等光催化剂可以 促进 $\alpha$-酮酸发生脱羧偶联反应，这些光催化剂由于具有 无需金属及廉价易得等优点表现出了巨大潜力和优势. 本文综述了近年来可见光诱导下 $\alpha$-酮酸参与有机反应 的最新进展，主要包括在酰基化和环化反应中的应用， 这些方法具有一些共同的优点, 例如无需金属试剂催 化、反应条件温和和反应效率高等，为 $\alpha$-酮酸在有机合 
成中的应用带来了新的思路和活力. 虽然有少数反应体 系不需要添加光催化剂, 利用反应物或者产物的自身光 学活性可以进行反应, 但是我们注意到前述多数反应还 需添加有机光催化剂. 这些有机光催化剂在反应后无法 有效回收利用, 只能作为污染物处理, 给环境造成一定 的负面影响. 针对上述局限, 还需要化学工作者继续努 力, 开发高效、可回收的新型光催化剂应用于 $\alpha$-酮酸的 有机光合成反应，进一步拓宽 $\alpha$-酮酸的应用范围.

\section{References}

[1] Ruan, L.; Chen, C.; Zhang, X.; Sun, J. Chin. J. Org. Chem. 2018, 38,3155 (in Chinese). (阮利衡, 陈春欣, 张晓欣, 孙京, 有机化学, 2018, 38, 3155.)

[2] Penteado, F.; Lopes, E. F.; Alves, D.; Perin, G.; Jacob, R. G.; Lenardao, E. J. Chem. Rev. 2019, 119, 7113.

[3] Wang, L.; Zhang, M.; Zhang, Y.; Liu, Q.; Zhao, X.; Li, J.-S.; Luo, Z.; Wei, W. Chin. Chem. Lett. 2020, 31, 67.

[4] Gui, Q.-W.; Teng, F.; Li, Z.-C.; Xiong, Z.-Y.; Jin, X.-F.; Lin, Y.-W.; Cao, Z.; He, W.-M. Chin. Chem. Lett. 2021, 32, 1907.

[5] He, F.-S.; Xie, S.; Yao, Y.; Wu, J. Chin. Chem. Lett. 2020, 31, 3065.

[6] Du, L.; Li, T. Chin. J. Org. Chem. 2020, 40, 140 (in Chinese). (杜琳琳, 李铁生, 有机化学, 2020, 40, 140.)

[7] Liu, J.; Xing, X.-N.; Huang, J.-H.; Lu, L.-Q.; Xiao, W.-J. Chem. Sci. 2020, 11, 10605.

[8] Yu, X.-Y.; Chen, J.-R.; Xiao, W.-J. Chem. Rev. 2021, 121, 506.

[9] Lu, J.; Li, L.; He, X.-K.; Xu, G.-Y.; Xuan, J. Chin. J. Chem. 2021, $39,1646$.

[10] Chen, Y.; Lu, L.-Q.; Yu, D.-G.; Zhu, C.-J.; Xiao, W.-J. Sci. China: Chem. 2019, 62, 24

[11] Gan, Z.; Li, G.; Yang, X.; Yan, Q.; Xu, G.; Li, G.; Jiang, Y.-Y.; Yang, D. Sci. China: Chem. 2020, 63, 1652.

[12] Gan, Z.; Li, G.; Yan, Q.; Deng, W.; Jiang, Y.-Y.; Yang, D. Green Chem. 2020, 22, 2956.

[13] Lü, Q.; Yu, B. J. Liaocheng Univ. (Nat. Sci. Ed.) 2019, 32, 28 (in Chinese). (吕琪妍, 於兵, 聊城大学学报(自然科学版), 2019, 32, 28.)

[14] Ren, L.; Ran, M.; He, J.; Qian, Y.; Yao, Q. Chin. J. Org. Chem. 2019, 39, 1583 (in Chinese). (任林静，苒茂刚，何佳芯，钱燕，姚秋丽，有机化学，2019，39， 1583.)

[15] Chen, J.; Li, Y.; Mei, L.; Wu, H. Chin. J. Org. Chem. 2019, 39, 3040 (in Chinese). (陈锦杨, 李玉涵, 梅兰, 吴红谕, 有机化学, 2019, 39, 3040.)

[16] Chen, D.; Liu, J.; Zhang, X.; Jiang, H.; Li, J. Chin. J. Org. Chem. 2019, 39, 3353 (in Chinese). (陈丹, 刘剑沉, 张馨元, 蒋合众, 李加洪, 有机化学, 2019, 39, 3353.)

[17] Yuan, X.; Yang, G.; Yu, B. Chin. J. Org. Chem. 2020, 40, 3620 (in Chinese) (袁晓亚, 杨国平, 於兵, 有机化学, 2020, 40, 3620.)

[18] Wang, C.; Zhou, L.; Yang, K.; Zhang, F.; Song, Q. Chin. J. Chem. 2021, 39, 1825.

[19] Liu, T.; Qu, C.; Xie, J.; Zhu, C. Chin. J. Org. Chem. 2019, 39, 1613 (in Chinese). (刘涛，屈川华，谢劲，朱成建，有机化学，2019, 39, 1613.)

[20] Chen, F.; Chen, H.; Wu, Q.; Luo, S. Chin. J. Org. Chem. 2020, 40, 339 (in Chinese). (陈锋, 陈浩, 吴庆安, 罗书平, 有机化学, 2020, 40, 339.)

[21] Zhou, R.; Ma, L.; Yang, X.; Cao, J. Org. Chem. Front. 2021, 8, 426.

[22] Lu, F.-D.; He, G.-F.; Lu, L.-Q.; Xiao, W.-J. Green Chem. 2021, 23 , 5379.

[23] Lang, Y.; Li, C.-J.; Zeng, H. Org. Chem. Front. 2021, 8, 3594.
[24] Meng, N.; Lv, Y.; Liu, Q.; Liu, R.; Zhao, X.; Wei, W. Chin. Chem. Lett. 2021, 32, 258.

[25] Wang, L.; Bao, P.; Liu, W.; Liu, S.; Hu, C.; Yue, H.; Yang, D.; Wei, W. Chin. J. Org. Chem. 2018, 38, 3189 (in Chinese). (王雷雷, 鲍鹏丽, 刘维伟, 刘思肜, 胡昌松, 岳会兰, 杨道山, 魏伟, 有机化学, 2018, 38, 3189.)

[26] Liu, J.; Liu, Q.; Yi, H.; Qin, C.; Bai, R.; Qi, X.; Lan, Y.; Lei, A. Angew. Chem., Int. Ed. 2014, 53, 502.

[27] Wang, H.; Xie, F.; Qi, Z.; Li, X. Org. Lett. 2015, 17, 920.

[28] Tan, H.; Li, H.; Ji, W.; Wang, L. Angew. Chem., Int. Ed. 2015, 54 , 8374.

[29] Shi, Q.; Li, P.; Zhu, X.; Wang, L. Green Chem. 2016, 18, 4916.

[30] Pawar, G. G.; Robert, F.; Grau, E.; Cramail, H.; Landais, Y. Chem. Commun. 2018, 54, 9337.

[31] Lv, Y.; Bao, P.; Yue, H.; Li, J.-S.; Wei, W. Green Chem. 2019, 21, 6051.

[32] Bao, P.; Liu, F.; Lv, Y.; Yue, H.; Li, J.-S.; Wei, W. Org. Chem. Front. 2020, 7, 492.

[33] Yang, J.; Song, M.; Zhou, H.; Wang, G.; Ma, B.; Qi, Y.; Huo, C. Org. Lett. 2020, 22, 8407.

[34] Zhu, D.-L.; Wu, Q.; Young, D. J.; Wang, H.; Ren, Z.-G.; Li, H.-X. Org. Lett. 2020, 22, 6832.

[35] Guillemard, L.; Colobert, F.; Wencel-Delord, J. Adv. Synth. Catal. 2018, 360, 4184 .

[36] Zhang, X.-Y.; Weng, W.-Z.; Liang, H.; Yang, H.; Zhang, B. Org. Lett. 2018, 20, 4686.

[37] Xie, L.-Y.; Bai, Y.-S.; Xu, X.-Q.; Peng, X.; Tang, H.-S.; Huang, Y.; Lin, Y.-W.; Cao, Z.; He, W.-M. Green Chem. 2020, 22, 1720.

[38] Shi, J.; Wei, W. Chin. J. Org. Chem. 2020, 40, 2170 (in Chinese). (时建伟, 魏伟, 有机化学, 2020, 40, 2170.)

[39] Wang, X.; Lei, J.; Li, G.; Meng, J.; Li, C.; Li, J.; Sun, K. Org. Biomol. Chem. 2020, 18, 9762.

[40] Yang, G.; Xie, X.; Cheng, M.; Gao, X.; Lin, X.; Li, K.; Cheng, Y.; Liu, Y. Chin. Chem. Lett. 2021, DOI: 10.1016/j.cclet.2021.08.037.

[41] Zhang, Z.; Song, X.; Li, G.; Li, X.; Zheng, D.; Zhao, X.; Miao, H.; Zhang, G.; Liu, L. Chin. Chem. Lett. 2021, 32, 1423.

[42] Tian, S.; Luo, T.; Zhu, Y.; Wan, J.-P. Chin. Chem. Lett. 2020, 31, 3073.

[43] Sun, K.; Xiao, F.; Yu, B.; He, W.-M. Chin. J. Catal. 2021, 42, 1921.

[44] Gao, F.; Lü, Q.; Yu, B. J. Liaocheng Univ. (Nat. Sci. Ed.) 2020, 33, 66 (in Chinese).

(高凡, 吕琪妍, 於兵, 聊城大学学报(自然科学版), 2020, 33, 66.)

[45] Shang, Z.-H.; Zhang, Z.-X.; Weng, W.-Z.; Wang, Y.-F.; Cheng, T.-W.; Zhang, Q.-Y.; Song, L.-Q.; Shao, T.-Q.; Liu, K.-X.; Zhu, Y.-P. Adv. Synth. Catal. 2021, 363, 490.

[46] Yang, G.; Li, K.; Lin, X.; Li, Y.; Cui, C.; Li, S.; Cheng, Y.; Liu, Y. Chin. J. Chem. 2021, 39, 3017.

[47] Mao, P.; Zhu, J.; Yuan, J.; Yang, L.; Xiao, Y.; Zhang, C., Chin. J. Org. Chem. 2019, 39, 1529 (in Chinese). (毛璞, 朱军亮, 袁金伟, 杨亮茹, 肖咏梅, 张长森, 有机化学, 2019, 39, 1529.)

[48] Monga, A.; Bagchi, S.; Soni, R. K.; Sharma, A. Adv. Synth. Catal. 2020, 362, 2232.

[49] Su, Y.; Zhang, R.; Xue, W.; Liu, X.; Zhao, Y.; Wang, K.-H.; Huang, D.; Huo, C.; Hu, Y. Org. Biomol. Chem. 2020, $18,1940$.

[50] Zhu, H.-L.; Zeng, F.-L.; Chen, X.-L.; Sun, K.; Li, H.-C.; Yuan, X.-Y.; Qu, L.-B.; Yu, B. Org. Lett. 2021, 23, 2976.

[51] Ji, W. Q.; Tan, H.; Wang, M.; Li, P. H.; Wang, L. Chem. Commun. 2016, 52, 1462.

[52] Zhao, B.; Zhang, Z.; Ge, Y.; Li, P.; Miao, T.; Wang, L. Org. Chem. Front. 2021, 8, 975.

[53] Zhang, J.-J.; Cheng, Y.-B.; Duan, X.-H. Chin. J. Chem. 2017, 35, 311.

[54] Jatoi, A. H.; Pawar, G. G.; Robert, F.; Landais, Y. Chem. Commun. 2019, 55, 466 . 